\title{
ON THE SIGNIFICANCE OF RESPIRATORY QUOTIENTS AFTER ADMINISTRATION OF CERTAIN CARBOHYDRATES
}

\author{
By WALTER R. CAMPBELL AND E. J. MALTBY \\ (From the Department of Medicine, University of Toronto)
}

(Received for publication June 13, 1928)

Following the administration of dihydroxyacetone there is a temporary increase in the carbon dioxide production and a secondary increase in the oxygen consumption, as has been shown by others as well as ourselves $(1,2,3,4,5)$. In some respects the results differ from those following glucose administration. The increase in $\mathrm{CO}_{2}$ occurs more sharply, that of oxygen gradually, but at the end of four hours the average oxygen consumption approximates that of the preliminary control period in both cases. The so-called respiratory quotient becomes very high (1.0 to 1.31) on account of the increased $\mathrm{CO}_{2}$ elimination and this has been interpreted as indicating a difference in the metabolism of the triose (increased combustion) as compared with glucose and has been advanced as evidence that dihydroxyacetone is metabolized more readily than glucose and is, therefore, more suitable for the treatment of diabetics than glucose itself.

The bulk of the other evidence on accurately controlled experimental animals is definitely opposed to this view and supports the opinion that the triose is converted into glucose prior to its utilization. On examination two inconsistencies reveal themselves: First, that a respiratory quotient above 1.0 should be regarded as signifying that a substance with a respiratory quotient of 1.0 is being burned; secondly, that the $\mathrm{CO}_{2}$ elimination precedes the increased oxygen intake. When we consider that a similar rise in oxygen absorption and $\mathrm{CO}_{2}$ elimination occurs in completely depancreatized animals fed the triose, even while they are excreting the equivalent of the triose given as glucose in the urine, this interpretation becomes remarkable and, we believe, untenable. 
Examination of the data $(1,2,4,5)$ indicates that hyperventilation has taken place and a cause for this is of interest. Increased oxygen consumption occurring later can then be explained on the basis of

TABLE 1

Dihydroxyacetone tolerance tests

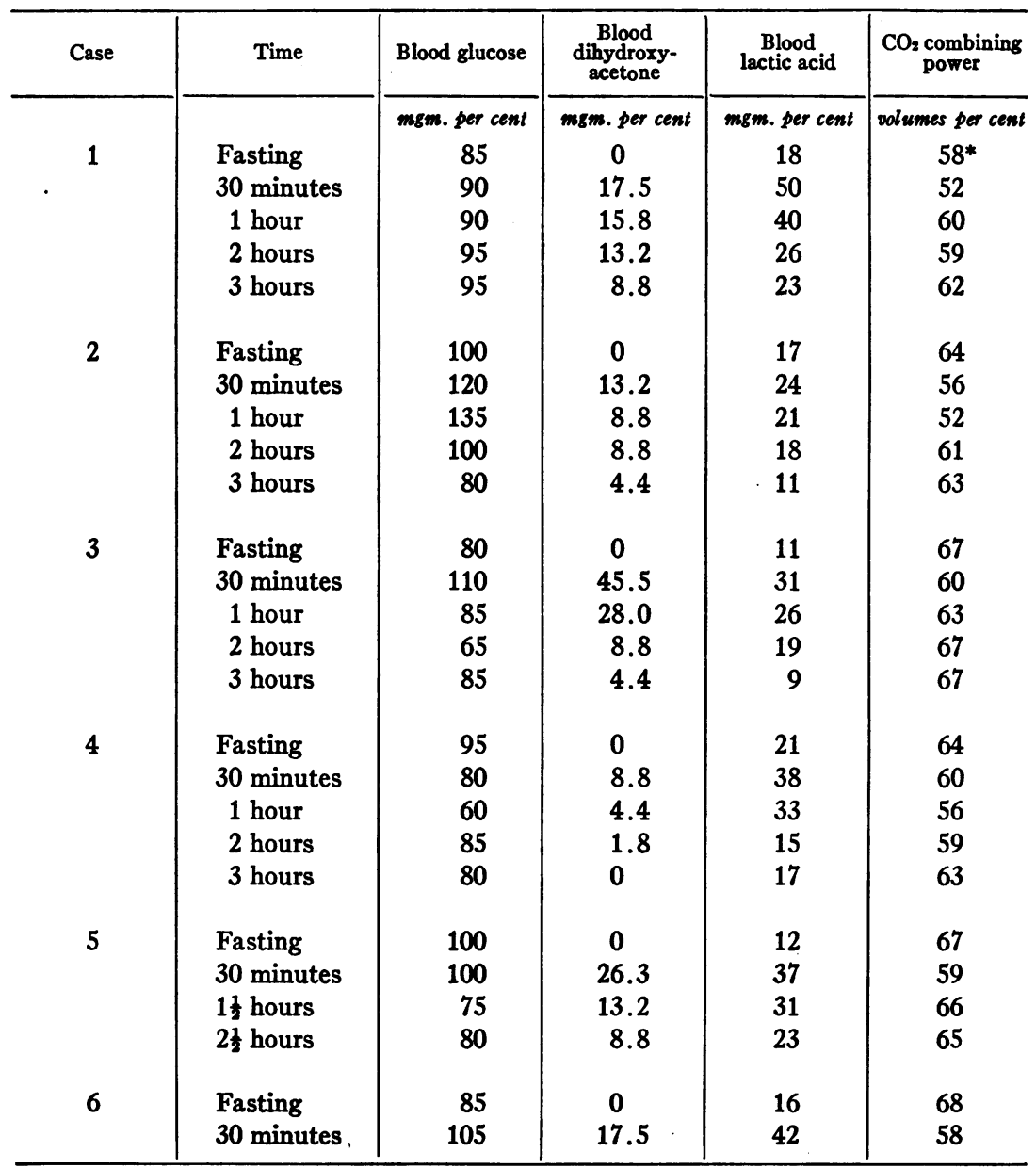

* First blood hemolyzed.

increased work necessitated by the hyperventilation and possibly also in other ways. Since it seemed apparent that hyperventilation was a 
probable feature of a period following administration of dihydroxyacetone and only to a minor extent follows glucose administration, it

TABLE 2

Fructose tolerance tests

\begin{tabular}{|c|c|c|c|c|c|}
\hline Case & Time & Blood glucose & Blood fructose & $\underset{\text { lactic acid }}{\text { Blood }}$ & $\mathrm{CO}_{2}$ pombining \\
\hline \multirow{6}{*}{7} & & mgm. per cent & mgm. per cent & mgm. per cent & oolumes per cent \\
\hline & Fasting & 90 & 0 & 12 & 59 \\
\hline & 30 minutes & 100 & 11.5 & 29 & 53 \\
\hline & 1 hour & 110 & 11.5 & 33 & 49 \\
\hline & 2 hours & 100 & 8.6 & 26 & 50 \\
\hline & 3 hours & 85 & 5.8 & 14 & 59 \\
\hline \multirow{5}{*}{8} & Fasting & 90 & 0 & 12 & 61 \\
\hline & 30 minutes & 90 & 8.6 & 23 & 59 \\
\hline & 1 hour & 90 & 8.6 & 25 & 59 \\
\hline & 2 hours & 95 & 5.8 & 19 & 58 \\
\hline & 3 hours & 85 & 2.9 & 14 & 59 \\
\hline \multirow{5}{*}{9} & Fasting & 80 & 0 & 16 & 62 \\
\hline & 30 minutes & 100 & 17.2 & 25 & 62 \\
\hline & 1 hour & 110 & 26.0 & 24 & 61 \\
\hline & 2 hours & 100 & 14.4 & 19 & 63 \\
\hline & 3 hours & 80 & 0 & 9 & 62 \\
\hline \multirow{4}{*}{10} & Fasting & 95 & 0 & 15 & 64 \\
\hline & $\begin{array}{l}30 \text { minutes } \\
1 \text { hour }\end{array}$ & 105 & 11.5 & 27 & 60 \\
\hline & 2 hours & 100 & 5.8 & 21 & 61 \\
\hline & 3 hours & 90 & 0 & 14 & 63 \\
\hline \multirow{5}{*}{11} & Fasting & 85 & 0 & 14 & 58 \\
\hline & 30 minutes & 90 & 2.9 & 24 & 60 \\
\hline & 1 hour & 110 & 5.8 & 19 & 61 \\
\hline & 2 hours & 125 & 5.8 & 16 & 57 \\
\hline & 3 hours & 95 & 0 & 12 & 61 \\
\hline \multirow{5}{*}{12} & Fasting & 110 & 0 & 21 & 63 \\
\hline & 30 minutes & 130 & 17.2 & 31 & 61 \\
\hline & 1 hour & 145 & 23.0 & 34 & 58 \\
\hline & 2 hours & 115 & 11.5 & 28 & 61 \\
\hline & 3 hours & 110 & 8.7 & 26 & 61 \\
\hline
\end{tabular}

became important to discover wherein the difference in the behavior of the sugars lies. As fructose, another ketose, sometimes causes the 
respiratory quotient to rise above 1.0 and similar claims have been made for it in diabetic treatment, it was included in the investigation along with cane sugar, which splits into glucose and fructose. Maltose, lactose, glucose and galactose, examples of aldoses, and the triatomic alcohol, glycerine, were selected for comparison with the above mentioned sugars.

TABLE 3

Sucrose tolerance tests

\begin{tabular}{|c|c|c|c|c|c|}
\hline Case & Time & Blood glucose & Blood fructose & $\begin{array}{c}\text { Blood } \\
\text { lactic acid }\end{array}$ & $\underset{\text { power }}{\mathrm{CO}_{2} \text { combining }}$ \\
\hline \multirow{6}{*}{13} & & $m g m$. per cent & mgm. per cent & mgm. per cent & volumes per cent \\
\hline & Fasting & 105 & 0 & 17 & 63 \\
\hline & 30 minutes & 150 & 15.6 & 23 & 59 \\
\hline & 1 hour & 190 & 21.0 & 25 & 54 \\
\hline & 2 hours & 145 & 15.6 & 24 & 60 \\
\hline & 3 hours & 110 & 0 & 17 & 60 \\
\hline \multirow{5}{*}{14} & Fasting & 95 & 0 & 28 & 60 \\
\hline & 30 minutes & 115 & 0 & 29 & 61 \\
\hline & 1 hour & 85 & 0 & 24 & 62 \\
\hline & 2 hours & 85 & 0 & 24 & 61 \\
\hline & 3 hours & & & & 63 \\
\hline \multirow{5}{*}{15} & Fasting & 100 & 0 & 10 & 65 \\
\hline & 30 minutes & 175 & 15.6 & 15 & 59 \\
\hline & 1 hour & 150 & 10.4 & 17 & 61 \\
\hline & 2 hours & 95 & 10.4 & 11 & 62 \\
\hline & 3 hours & 65 & 0 & 9 & 65 \\
\hline \multirow{5}{*}{16} & Fasting & 100 & 0 & 11 & 61 \\
\hline & 30 minutes & 120 & 5.2 & 12 & 59 \\
\hline & 1 hour & 155 & 10.4 & 17 & 56 \\
\hline & 2 hours & 130 & 5.2 & 11 & 60 \\
\hline & 3 hours & 95 & 0 & 10 & 61 \\
\hline
\end{tabular}

Disturbance of the acid alkali balance is perhaps the most potent cause of hyperventilation, and for its measurement the $\mathrm{CO}_{2}$ combining power (Van Slyke's precision method (6)) was employed. For certain reasons which will be discussed later the change encountered cannot be the maximal one, but it is sufficiently great to exceed many times the possible error. The origin of the change in $\mathrm{CO}_{2}$ combining power which preliminary tests showed to be present was not far to 
seek. Embden and co-workers (7) found that; as well as the triose becoming glucose when perfused through surviving liver, the profused blood also contains much lactic acid. In our work estimations of blood lactic acid were made by the Clauson method as improved by Shaffer and his co-workers (8).

TABLE 4

Glucose tolerance test

\begin{tabular}{|c|c|c|c|c|}
\hline Case & Time & Blood glucose & $\begin{array}{c}\text { Blood } \\
\text { lactic acid }\end{array}$ & $\begin{array}{c}\mathrm{CO}_{2} \text { combining } \\
\text { power }\end{array}$ \\
\hline \multirow{5}{*}{17} & & mẹm. per cent & mgm. per cent & volumes per cent \\
\hline & $\begin{array}{l}\text { Fasting } \\
30 \text { minutes }\end{array}$ & $\begin{array}{r}95 \\
130\end{array}$ & $\begin{array}{l}10 \\
10\end{array}$ & $\begin{array}{l}65 \\
65\end{array}$ \\
\hline & 1 hour & 160 & 11 & 62 \\
\hline & 2 hours & 150 & 11 & 66 \\
\hline & 3 hours & 75 & 11 & 65 \\
\hline \multirow{5}{*}{18} & Fasting & 95 & 15 & 65 \\
\hline & 30 minutes & 125 & 17 & 62 \\
\hline & 1 hour & 100 & 17 & 64 \\
\hline & 2 hours & 95 & 15 & 63 \\
\hline & 3 hours & 80 & 14 & 63 \\
\hline \multirow{5}{*}{19} & Fasting & 90 & 10 & 57 \\
\hline & 30 minutes & 85 & 15 & 60 \\
\hline & 1 hour & 105 & 12 & .60 \\
\hline & 2 hours & 95 & 9 & 59 \\
\hline & 3 hours & 105 & 9 & 59 \\
\hline \multirow{5}{*}{20} & Fasting & 90 & 14 & 61 \\
\hline & 30 minutes & 135 & 15 & 64 \\
\hline & 1 hour & 135 & 14 & 64 \\
\hline & 2 hours & 120 & 11 & 61 \\
\hline & 3 hours & 100 & 12 & 61 \\
\hline
\end{tabular}

Because of the amounts of blood required for duplicate analyses and the effect of hemorrhage on the blood lactic acid of small animals these experiments were carried out on man. In most cases convalescent patients were the subjects, care being taken that no metabolic abnormalities were present and the patient well recovered from his disease. Some cases were patients awaiting operations of election. A few were selected deliberately because they were suffering from liver in- 
jury due to arsphenamine and were undergoing a parallel investigation at the time. (Cf. table 10.) The preparation was the same as for the ordinary blood sugar tolerance test, the patient remaining quiet in bed, fasting for fifteen hours and receiving 100 grams of the particular sugar dissolved in 250 cubic centimeters of water. Blood samples

TABLE 5

Maltose tolerance test

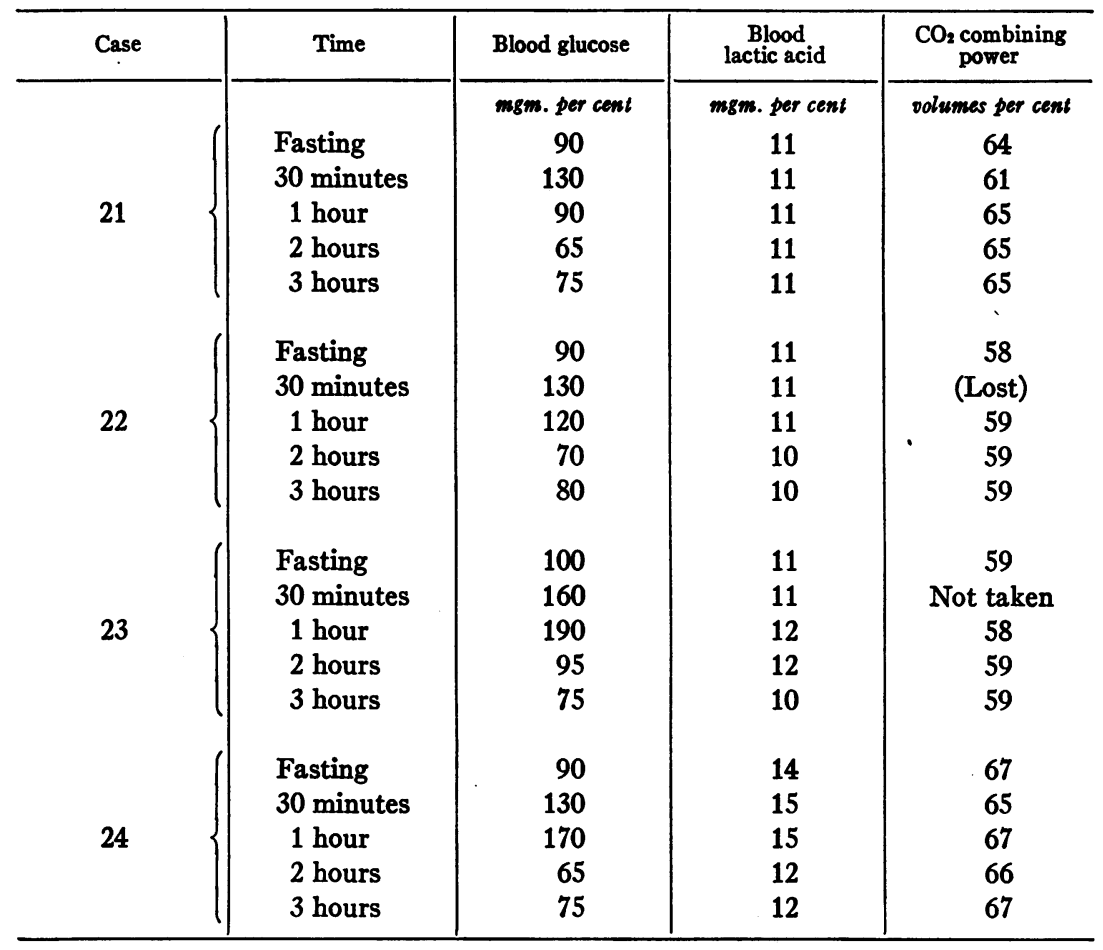

were removed while fasting, 30 minutes, and also one hour, two hours and three hours after administration of the sugar, and the appropriate analytical treatment for the various tests commenced at once. The results of the analyses after administration of dihydroxyacetone, fructose, cane sugar, glucose, maltose, lactose, galactose, and glycerine are tabulated in tables 1 to 8 . 
TABLE 6

Lactose tolerance test

\begin{tabular}{|c|c|c|c|c|}
\hline Case & Time & Blood glucose & $\begin{array}{c}\text { Blood } \\
\text { lactic acid }\end{array}$ & $\begin{array}{c}\mathrm{CO}_{2} \text { combining } \\
\text { power }\end{array}$ \\
\hline \multirow{6}{*}{25} & & mgm. per cent & mgmi. per cent & volumes per cent \\
\hline & Fasting & 95 & 15 & 61 \\
\hline & 30 minutes & 100 & 17 & 61 \\
\hline & 1 hour & 105 & 17 & 62 \\
\hline & 2 hours & 105 & 17. & 61 \\
\hline & 3 hours & 120 & 14 & 59 \\
\hline \multirow{5}{*}{26} & Fasting & 90 & 14 & 61 \\
\hline & 30 minutes & 95 & 17 & 60 \\
\hline & 1 hour & 95 & 16 & 60 \\
\hline & 2 hours & 90 & 15 & 61 \\
\hline & 3 hours & 95 & 15 & 61 \\
\hline \multirow{5}{*}{27} & Fasting & 95 & 15 & 63 \\
\hline & 30 minutes & 145 & 21 & 61 \\
\hline & 1 hour & 155 & 19 & 61 \\
\hline & 2 hours & 140 & 18 & 63 \\
\hline & 3 hours & 75 & 16 & 65 \\
\hline
\end{tabular}

TABLE 7

Galactose tolerance test

\begin{tabular}{|c|c|c|c|c|}
\hline Case & Time & Blood glucose & $\begin{array}{c}\text { Blood } \\
\text { lactic acid }\end{array}$ & $\underset{\text { power }}{\mathrm{CO}_{2} \text { combining }}$ \\
\hline \multirow{6}{*}{28} & & mgm. per cent & mgm. per cent & volumes per cent \\
\hline & Fasting & 95 & 14 & 66 \\
\hline & 30 minutes & 15 & 17 & 65 \\
\hline & 1 hour & 205 & 12 & 64 \\
\hline & 2 hours & 235 & 14 & 66 \\
\hline & 3 hours & 190 & 13 & 67 \\
\hline \multirow{5}{*}{29} & Fasting & 95 & 14 & 62 \\
\hline & 30 minutes & 125 & 15 & 62 \\
\hline & 1 hour & 170 & 15 & 61 \\
\hline & 2 hours & 240 & 14 & 62 \\
\hline & 3 hours & 215 & 19 & 62 \\
\hline \multirow{5}{*}{30} & Fasting & 100 & 17 & 65 \\
\hline & 30 minutes & 155 & 17 & 64 \\
\hline & 1 hour & 210 & 18 & 62 \\
\hline & 2 hours & 150 & 19 & 61 \\
\hline & 3 hours & 105 & 18 & 63 \\
\hline
\end{tabular}


TABLE 8

Glycerine tolerance test

\begin{tabular}{|c|c|c|c|c|}
\hline Case & Time & Blood glucose & $\begin{array}{c}\text { Blood } \\
\text { lactic acid }\end{array}$ & $\underset{\text { power }}{\mathrm{CO}_{2} \text { combining }}$ \\
\hline \multirow{6}{*}{31} & & msm. per cent & mgm. per cont & oolumes per cent \\
\hline & Fasting & 90 & 10 & 57 \\
\hline & 30 minutes & 95 & 10 & 57 \\
\hline & 1 hour & 95 & 15 & 61 \\
\hline & 2 hours & 95 & 12 & 58 \\
\hline & 3 hours & 95 & 10 & 58 \\
\hline \multirow{5}{*}{32} & Fasting & 90 & 14 & 62 \\
\hline & 30 minutes & 105 & 14 & 61 \\
\hline & 1 hour & 110 & 12 & 62 \\
\hline & 2 hours & 110 & 12 & 62 \\
\hline & 3 hours & 100 & (Lost) & 61 \\
\hline \multirow{5}{*}{33} & Fasting & 85 & 12 & 67 \\
\hline & 30 minutes & 80 & 14 & 69 \\
\hline & 1 hour & 80 & 12 & 70 \\
\hline & 2 hours & 80 & 12 & 68 \\
\hline & 3 hours & 80 & 12 & 68 \\
\hline
\end{tabular}

TABLE 9

Lactic acid tolerance test

\begin{tabular}{|c|c|c|c|c|}
\hline Case & Time & Blood glucose & $\begin{array}{c}\text { Blood } \\
\text { lactic acid }\end{array}$ & $\mathrm{CO}_{\text {power }}^{\text {combining }}$ \\
\hline \multirow{6}{*}{34} & & mom. per cont & mgm. per cont & oolumes per cent \\
\hline & Fasting & 90 & 11 & 63 \\
\hline & 30 minutes & 90 & 19 & 60 \\
\hline & 1 hour & 95 & 19 & 56 \\
\hline & 2 hours & 100 & 14.5 & 61 \\
\hline & 3 hours & 95 & 11 & 61 \\
\hline \multirow{5}{*}{35} & Fasting & 95 & 11 & 61 \\
\hline & 30 minutes & 90 & 19 & 58 \\
\hline & 1 hour & 90 & 17 & 60 \\
\hline & 2 hours & 90 & 14.5 & 60 \\
\hline & 3 hours & 90 & 11 & 60 \\
\hline
\end{tabular}


TABLE 10

Clinical diagnoses of subjects

Dihydroxyacetone............




\section{DISCUSSION}

It will be noted that the results fall into two groups, the first three sugars causing a reduction in $\mathrm{CO}_{2}$ combining power, the others not. Associated with the fall in $\mathrm{CO}_{2}$ combining power is a definite increase in the blood lactic acid, more marked in the case of dihydroxyacetone than with fructose or cane sugar as would be expected from the relative amounts of reduction of the $\mathrm{CO}_{2}$ combining power in these cases. Moreover, the return to previous values for $\mathrm{CO}_{2}$ combining power and blood lactic acid runs parallel. As in the case of the $\mathrm{CO}_{2}$ combining power alterations in the blood lactic acid after administration of the other sugars are practically negligible. In order to gain some idea of the changes involved two men were given five grams of pure lactic acid dissolved in 250 cubic centimeters of water sweetened with saccharin, and tests similar to the foregoing carried out. Table 9 shows the results obtained. In this connection it should be pointed out that lactic acid in the body is constantly being burned or reconverted to glucose or glycogen so that the values obtained for blood lactic acid as well as the resultant lowering of $\mathrm{CO}_{2}$ combining power fall . short of measuring the total change taking place. Particularly will this be important in the later phases owing to the increased oxygenation consequent upon the hyperventilation. (Also since the respiratory muscles work on carbohydrate we must expect a shift of respiratory quotient toward 1.0.)

To take one method of calculating the $\mathrm{CO}_{2}$ eliminated: Palmer and Van Slyke (9) have shown that it requires 1.0 gram of $\mathrm{NaHCO}_{3}$ to raise the $\mathrm{CO}_{2}$ combining power one volume per cent in an individual weighing 38 kilograms. Taking the average depression ${ }^{1}$ of the $\mathrm{CO}_{2}$ combining power at the half hour period as amounting to eight volumes per cent in an individual of 70 kilograms, 14 grams of $\mathrm{NaHCO}_{3}$ have been lost, equal to one-sixth of a formula weight or $3,750 \mathrm{cc}$. of $\mathrm{CO}_{2}$ released. Providing this patient were in a basal state, 1 calorie per kilogram hour should approximate his needs, or 35 calories the requirement for the half-hour, or $7,300 \mathrm{cc}$. of oxygen. With a true respiratory quotient of 0.80 (it would undoubtedly be higher on ac-

${ }^{1}$ Omitting from the average Case IV which requires one hour to attain this reduction in $\mathrm{CO}_{2}$ combining power. 
count of the increased muscle work of respiration) the $\mathrm{CO}_{2}$ production would be $5,840 \mathrm{cc}$. Adding to this $3,750 \mathrm{cc}$. $\mathrm{CO}_{2}$ driven off by the production of lactic acid the $\mathrm{CO}_{2} / \mathrm{O}_{2}$ ratio becomes 1.31. Had the basal respiratory quotient actually been 1.0 the additional liberation of $\mathrm{CO}_{2}$ would have forced it up to 1.50 . It may be recalled that using a method for determining total oxygen consumption and carbon dioxide elimination we have not found $\mathrm{CO}_{2} / \mathrm{O}_{2}$ ratios exceeding 1.10 (5).

Or to take an example from Mason's paper (Jour. Clin. Invest., 1925, ii, 522) in which he administers 50 grams of dihydroxyacetone to a man of twenty-six with a surface area of $1.525 \mathrm{sq}$. m.:

\section{Basal $\mathrm{CO}_{2}$ elimination at true rate of $10,780 \mathrm{cc}$. per hour Basal $\mathrm{O}_{2}$ absorption at true rate of $12,120 \mathrm{cc}$. per hour True basal R.Q. $=0.888$}

After 30 minutes a second examination shows the

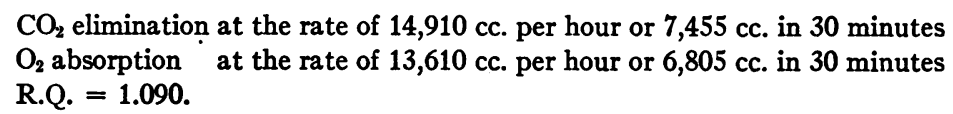

Evidently this rate is near the maximal since in the examination made one hour after the dihydroxyacetone administration the $\mathrm{O}_{2}$ and $\mathrm{CO}_{2}$ are nearly back to the basal and the respiratory quotient is again 0.890 . Evidently, also, since the discontinuous method of examination was used during the period 20 to 30 minutes after ingestion of the triose the additional $\mathrm{CO}_{2}$ actually eliminated in the first half hour cannot be more than one-quarter the difference between the basal value per hour and the observed value per hour, or about one liter. As we have seen, a minimal average depression of the $\mathrm{CO}_{2}$ combining power of eight volumes per cent would provide 3,750 cubic centimeters of $\mathrm{CO}_{2}$ to be eliminated but as 100 grams of the triose were used instead of 50 grams, as in Mason's work, $1,875 \mathrm{cc}$. might be expected to be eliminated by a $70 \mathrm{kgm}$. man. The margin appears to be quite adequate to explain the actual result even in an individual weighing much less than $70 \mathrm{kgm}$., even without regard to the fact that such an additional amount of $\mathrm{CO}_{2}$ to be eliminated would require increased respiratory work as must have been the case from the additional amount of oxygen consumed.

No doubt also, considering that all the sugar cannot have been 
absorbed in the first half hour, the formation of more lactic acid may be expected as this remaining sugar reaches the liver. It is evident from the tables that some lactic acid has disappeared at the end of an hour but a continuance of a high respiratory quotient may depend in part on incomplete re-establishment of acid alkali equilibrium, or combustion of the lactic acid, or many other factors. Should the initial $\mathrm{CO}_{2}$ released be eliminated over a longer period, as there is good reason to believe possible, there is quite sufficient to maintain high $\mathrm{CO}_{2} / \mathrm{O}_{2}$ ratios for a considerable period. Attention may be called to the fact that the higher values for these ratios reported have been obtained for a very limited period and calculated on the hour basis, a procedure which examination of the protocols in the preceding paper shows is unsuitable and liable to lead to erroneous conclusions.

Turning now to another aspect of these results, we wish to call attention to the remarkable parallelism between the changes in $\mathrm{CO}_{2}$ combining power and blood lactic acid in these cases with the results of the respiratory examination in man (Mason's) or in normal dogs following the administration of dihydroxyacetone as recorded in the preceding paper. In contrast the fixation of $\mathrm{CO}_{2}$ and blood lactic acid in man and the slow rise and fall of the $\mathrm{CO}_{2} / \mathrm{O}_{2}$ ratio after glucose administration to man or animals inspires confidence that such extraneous factors play little, if any, part in the alterations of the respiratory quotient after administration of the normal body sugar.

Corresponding to the decreased frequency with which the $\mathrm{CO}_{2} / \mathrm{O}_{2}$ ratio exceeds 1.0, the results with fructose are somewhat less striking both in the reduction of $\mathrm{CO}_{2}$ combining power and increase in the lactic acid level (table 2). With them, however, it is still possible to calculate a $\mathrm{CO}_{2} / \mathrm{O}_{2}$ ratio well above 1.0. Sucrose also shows a smaller change in the $\mathrm{CO}_{2}$ combining power and blood lactic acid (table 3). Half the administered carbohydrate was really glucose when it reached the liver and, as shown in table 4, glucose has no effect on either $\mathrm{CO}_{2}$ combining power or blood lactic acid. Likewise, maltose and lactose and galactose have no influence on these (tables 5, 6 and 7).

It would seem apparent that the extraordinary $\mathrm{CO}_{2} / \mathrm{O}_{2}$ ratios reported by others $(1,2,3,4)$, as well as ourselves (5), after administration of certain carbohydrates are consequentially related to the production of lactic acid in the body and the blowing off of $\mathrm{CO}_{2}$ neces- 
sitated thereby. In such case the inferences drawn from them by various observers who have regarded them as true respiratory quotients must be revised and the problem becomes exceedingly complex. To eliminate an extra amount of $\mathrm{CO}_{2}$ only somewhat smaller than the elimination under basal conditions must entail additional muscular work. According to the present accepted opinion this work must be done principally at the expense of the muscle glycogen stores, and in turn these stores kept full by transfer of carbohydrate from elsewhere. In all probability, as Hill and his co-workers have shown, the respiratory quotient of the additional work for short periods will approach unity and necessarily the output of $\mathrm{CO}_{2}$ and the oxygen consumption will rise independently of any considerations as to the kind of foodstuff being ingested. In addition, however, we have to deal with a rapid production of lactic acid in considerable amounts. The heat production in this case is anerobic but additional oxygen is required to convert it into its final forms - glycogen, carbon dioxide and waterand this must tend to increase the oxygen consumptions and $\mathrm{CO}_{2}$ elimination and raise the respiratory quotient toward unity since the respiratory quotient of this process is 1.0.

Now that it is becoming clearer that all, or about all, foodstuffs must be utilized as glucose, the latter assumes a unique position in the body. The site of transformation into glucose in the case of dihydroxyacetone (10) and fructose $(11,12)$ has been shown to be the liver and other evidence points to this organ playing an important rôle in the transformation of proteins and fat. The meaning of the production of considerable amounts of lactic acid when certain sugars are being converted to glucose presents some speculative interest. It may be suggested that when glycogen is present in the liver it can be used to furnish energy for other processes. In this case the first step is conversion of glycogen to lactic acid, an anerobic process yielding 0.72 calorie per gram of lactic acid produced. It may be suggested that this energy would provide the small energy deficit between fructose and glucose and presumably (though no data on this point exists) between dihydroxyacetone and glucose. The other sugars tested have as high, or higher, energy value as glucose. Because of its high energy value and the fact that it also is known to be converted to glucose in the depancreatized animal (13) glycerine was tested in the same 
way as the sugars. As table 8 shows, no lowering of $\mathrm{CO}_{2}$ combining power or rise in blood lactic acid occurs, a result which is at least consistent with this viewpoint, though by no means confirmatory of it.

Whether it be true or not that it provides the necessary chemical energy for the conversion of the ketoses to glucose, a further implication of the lactic acid production by these sugars occurs to one. For some reason lactic acid is produced when the triose or fructose is fed. The only source of lactic acid known to occur in the body is glucose or glycogen. If it could be produced from triose itself the triose administered intravenously to eviscerated animals would not remain unchanged (9). The process glycogen $\rightarrow$ lactic acid involves an energy reduction change which must be charged against the foodstuffs initiating the lactic acid production. As, according to Meyerhof, this reduction amounts to 0.72 calorie per gram of lactic acid produced, a considerable reduction in the physiological caloric value of the foodstuff is caused directly as well as through the extra work induced by the acid stimulating respiration. In our opinion such an action does not enhance the therapeutic value of either sugar in diabetes. It is perhaps not a fortuitous circumstance that most of the important carbohydrate used by man and animals is convertible directly to glucose before absorption.

\section{SUMMARY AND CONCLUSIONS}

The results of the examination of the carbon dioxide combining power and blood lactic acid after the administration of certain carbohydrates have been tabulated and discussed. Certain sugarsdihydroxyacetone, fructose and cane sugar-cause a lowering of the carbon dioxide combining power and a rise in the blood lactic acid, while glucose, maltose, lactose, galactose and glycerine do not. These changes take place at the proper time to cause stimulation of respiration and the increased elimination of carbon dioxide noted when such substances are fed and explain the extraordinarily high' $\mathrm{CO}_{2} / \mathrm{O}_{2}$ ratios found. We would conclude that such ratios cannot be used as an index of food transformation, combustion or storage of the first substances mentioned. There appears no reason to believe that these factors interfere in the use of the ratios as respiratory quotients in the case of the other sugars examined. In view of the additional energy 
required, because of the stimulation of respiration and that lost by conversion of glycogen to lactic acid we cannot regard the first named sugars as being more valuable in the treatment of diabetes than glucose itself.

\section{BIBLIOGRAPHY}

1. Mason, E. H., J. Clin. Invest., 1925-26, ii, 521. Dihydroxyacetone Studies. I. Its Respiratory and Carbohydrate Metabolism in Normal Men.

2. Mason, E. H., J. Clin. Invest., 1925-26, ii, 533. Dihydroxyacetone Studies. II. Its Respiratory and Carbohydrate Metabolism in Diabetes Mellitus.

3. Himwich, A. E., Rose, M. I., and Malev, M. R., Proc. Soc. Exp. Biol. and Med., 1926-7, xxvii, 238. Changes in the Respiratory Quotient Produced by Subcutaneous Injection of Dioxyacetone and Glucose.

4. Lambie, C. G., and Redhead, F. A., Biochem. J., 1927, xxi, 549. Studies in Carbohydrate Metabolism. III. The Influence of Dihydroxyacetone upon the Respiratory Metabolism and upon the Inorganic Phosphate of the Blood.

5. Campbell, W. R., and Soskin, S., J. Clin. Invest., 1928, vi, 291. On the Gaseous Exchange Following the Administration of Dihydroxyacetone.

6. Van Slyke, D. D., and Stadie, W. C., J. Biol. Chem., 1921, xlix, 1. The Determination of the Gases of the Blood.

7. Embden, G., Baldes, K., and Schmitz, E., Biochem. Ztschr., 1912, xlv, 108. Uber den Chemismus der Milchsäurebildung aus Traubenzucker im Tierkörper.

8. Friedemann, T. E., Cotonio, M., and Shaffer, P. A., J. Biol. Chem., 1927, 1xxiii, 335. The Determination of Lactic Acid.

Davenport, H. A., and Cotonio, M., J. Biol. Chem., 1927, lxxiii, 359. A Condenser Unit for Use in Determination of Lactic Acid.

Ronzoni, E., and Wallen-Lawrence, Z., J. Biol. Chem., 1927, lxxiv, 363. Determination of Lactic Acid in Blood.

9. Palmer, W. W., and Van Slyke, D. D., J. Biol. Chem., 1917, xxxii, 499. Studies of Acidosis. IX. Relationship between Alkali Retention and Alkali Reserve in Normal and Pathological Individuals.

10. Markowitz, J., and Campbell, W. R., Am. J. Physiol., 1927, lxxx, 548. The Fate of Dihydroxyacetone in the Animal Body.

11. Mann, F. C., Personal communication.

12. Campbell, W. R., and Soskin, S., Unpublished experiments.

13. Campbell, W: R., and Markowitz, J., J. Clin. Invest., 1927, iv, 37. Preferential Utilization of Carbohydrate in Diabetes. 